\title{
Prevalence Rate of Hepatitis-B Virus Infection in the Niger Delta Region of Nigeria using a Graph-Diffusion Heuristic Model
}

\author{
A. A. Ojugo \\ Department of Computer Science, Federal \\ University of Petroleum Resources \\ Effurun, Delta State, \\ Nigeria
}

\author{
I. P. Okobah \\ Department of Computer Science Education, \\ Federal College of Education Technical \\ Asaba, Delta State, \\ Nigeria
}

\begin{abstract}
It is known that vaccination against the hepatitis-B virus (HBV) and its infection in Nigeria, is lower than many subSaharan African countries. In Nigeria, HBV is reported to be the most common causative of liver disease. Many studies have ensued in this regard, to ascertain the extent of HBV exposure amongst Nigerians - as the average risk is unknown. We aim to predict an estimated HBV prevalence rate in Niger Delta, and prevalence within the sub-groups. We use 30,000 HBV-cases as predicted using the supervised models below. Result shows HBV infection is quite hyper endemic in Nigeria, and trends as the highest cause of chronic liver disease in Sub- Sahara Africa. Study suggests that large numbers of pregnant women and children were exposed to $\mathrm{HBV}$; and increased efforts geared towards preventing new HBV infections are urgently needed in Nigeria
\end{abstract}

\section{Keywords}

Hepatitis, classification, Nigeria.

\section{INTRODUCTION}

THE liver is a wedge-shaped organ in the upper right side of the body beneath the rib cage. It is considered to be the largest organ and equates to 2-to-3 percent of the overall body's mass. The liver (unlike the heart and stomach) has over 140 functions (WHO, 2000) - which includes (not limited to) generates required amount of bile used for digestion, piles up minerals and vitamins, assists in blood clotting (vitamin $\mathrm{K}$ ), deactivates toxic, regulates energy, sustains hormonal balance, produces amino-acids to build strong muscles and processes sedatives (WHO, 1999). There is a growing rise in the number of patients fatally attacked by chronic liver diseases - resulting from excess intake of alcohol, inhale of harmful gases, intake of contaminated food, pickles and drugs. Thus, liver disease presents a number of concerns in health-care delivery. Chronic liver disease has become a common long-term condition and issue of great concern, to both the developed and developing world. There exists many classification heuristics to help in its early identification and diagnosis - as it is vital for survival of the patients (Hashrem and Mabrouk, 2014).

\subsection{Types of Hepatitis Virus}

The inflammation (itis) of a liver (hepar), and the burning or swelling of the liver cells is widely known as hepatitis. There are several sources of hepatitis, comprising of viral infections A, B and C. Others include auto-immune hepatitis, fatty liver hepatitis, spirituous hepatitis and toxin induced hepatitis (WHO, 2000; Hodgson, Harrison and Cross, 2006; Moriishi and Matsuura, 2003). On the worldwide stage, it is predicted that around 250 million people are affected by hepatitis $\mathrm{C}$.
Also, it is estimated 400million people are chronic haulers of hepatitis B (WHO, 2000).

When an individual becomes infected with hepatitis virus, this virus assaults the liver, causing an instant swelling and redness of the liver (Yasin et al, 2011). Studies have shown there is a high probability one may have encountered at least one or more persons with it. Often people with hepatitis virus find it easy to live their lives without letting others know about it - because, hepatitis may be infectious. By doing so, they thwart themselves either from facing the ignorant attitude or sympathy of others. Those living with infectious hepatitis need only take a few precautions to avoid passing the virus around (Moriishi and Matsuura, 2003; Fattovich and Schalm, 2000 and Lawrence, 2000).

\subsection{Symptoms and Diagnosis of the HBV Infection}

Most infections occur during infancy or childhood, and are rarely diagnosed, since there may be few obvious symptoms. Symptoms of a new infection may not be apparent in children under 5-years of age and adults with a suppressed immune system. Among those aged 5 years and over, between 30 and 50 percent will show initial signs and symptoms. It includes: (a) fever, (b) vomiting, (c) fatigue, (d) nausea, (e) joint pain, (f) loss of appetite, (g) abdominal pain, (h) dark urine, (i) clay-colored stools, (j) jaundice, and/or (k) a yellowing of the skin and whites of the eyes. Acute symptoms appear from 60 to 120 days after exposure to the virus, and they can last from several weeks to 6 months. A person with chronic HBV infection may have ongoing episodes of abdominal pain, persistent fatigue, and aching joints (Davis, 2018).

Blood test helps diagnose acute and chronic HBV infection. Screening is available for people with high-risk of exposure or complications due to undiagnosed HBV infection. As thus, such population recommended for HBV screening includes the following: (a) Infants of mothers with HBV, (b) infected sex partners, (c) unprotected sex with multiple partners, (d) gay sex, (e) Injection drug users, (f) people living with someone who has chronic HBV infection, (g) health-care and public safety workers at risk from occupational exposure from blood-contaminated body fluid, (h) hemodialysis patient, (i) person receiving chemotherapy for cancer, (j) persons from a regions with high incidence of $\mathrm{HBV}$, including some Asian countries, (k) pregnant women (Wilkins et al, 2010). Also, if a woman has HBV during pregnancy, the newborn must be vaccinated and receive hepatitis B immune globulin (HBIG) within 12 to 24 hours after birth (Davis, 2018). 


\subsection{HBV Infection in Nigeria}

Aminu and Vandu (2014) Hepatitis-B is a DNA virus of the family Hepadnaviridae, and a causative agent of the hepatitis$\mathrm{B}$ infection. HBV is the most common infectious diseases in the world and a major health problem. Emechebe et al, (2009) WHO estimates a world-population of over 2-billion people with serologic evidence of HBV infection (past and present);

And, over 350-million are chronically infected and at risk for $\mathrm{HBV}$-related liver disease. It is over 50-times more infectious than HIV, and 10-times more infectious than Hepatitis-C, as many carriers do not realize they are infected with the virus. It is a common causative of liver diseases, chronic infection and death associated with liver failure, liver cancer and cirrhosis (Shepard et al, 2006; Weinbaum et al, 2008).

The virus has caused severe endemic in parts of Africa and Asia. The prevalence of $\mathrm{HBV}$ varies between $2 \%$ in developed countries to about $8 \%$ in developing countries, where infection is endemic with sex, age and socio-economic status - all of which unveils as important risk factors for infection (Drostein et al, 2004). The degree of its endemicity often correlates with predominant mode of transmission. The hepatitis disease has enormous impact on health and national economy of many countries, and its severity is highly variable and unpredictable (Adoga et al, 2010). The minimum infectious dose is so low that such practices like sharing of tooth brush or a razor blade can transmit infection (Odusanya et al, 2005).

HBV is a blood borne and sexually transmitted pathogen that is spread via contaminated blood or other body fluids (saliva, sweat, semen, vaginal secretion, breast milk, urine and feaces). Transmission can occur when using the same syringe as an infected person, from blood transfusions, body piercing or tattoos, mother-to-child birth, occupational exposure, medical procedures, and sexual intercourse. HBV shares similar routes of transmission with HIV (Chang, 2007), and there are four known transmission modes (Viral Hepatitis Prevention Board, 1996) namely: (a) mother-to-child birth (prenatal), (b) contact with infected person, (c) sexual contact, and (d) exposure to blood or other infected fluids. Because HBV can remain stable and infectious on environmental surfaces for at least 7-days, transmission may occur indirectly via contaminated surfaces and other objects like tooth brush, baby bottles, razors, eating utensil, hospitals equipment, contact with mucous membranes, and/or open skin breaks (Wiley et al, 2011).

HBV disease affects people of all age-groups; but, it has been found from studies to predominantly infect young adults, and acquired sexually or by injecting drug use (Shepard et al, 2006). Most people who become infected with HBV are able to clear the virus from their blood stream within 6 months of post infection and develop immunity. Those who have not cleared the virus after 6 months are considered to have chronic HBV infection. The risk of death from HBV-related liver cancer or cirrhosis is approximately $25 \%$ for persons who acquire chronic infection at childhood. Moreover, $8 \%$ to $10 \%$ of people in the general population in developing countries become chronically infected and most acquire infection with $\mathrm{HBV}$ at childhood (Weinbaum et al, 2008; WHO, 2009). Nigeria is classified among the group of countries highly endemic for HBV infection. And, over 75\% of Nigerians have reportedly been exposed to HBV at one time or the other in their life. Although hepatitis B vaccination is highly effective in preventing infection with $\mathrm{HBV}$ and consequent acute and chronic liver disease, this infection is still a major problem in Nigeria as reported by various workers (Weinbaum et al, 2008; Adoga et al, 2010 and Luka et al, 2008).

\section{THE GRAPH-MODEL AS A DIFFUSION FRAMEWORK}

Graphs have become the dominant life-form of many tasks. It advances the study of graphs and applications, which have been successfully applied to many disciplines (Pavlopoulos et al, 2011). In analyzing graphs, we seek parametric indicators (depending on the nature of the task at hand), which raises new questions such as: (a) what parameters are required for its threshold prediction with perturbations in the graph, (b) what behaviour changes are expected (as local feats in a node may emerge as global paths), and (c) what boundary limits must be set for such feats predictions (Tiovonen et al, 2009; Fionda, 2012; Ojugo et al, 2016).

\subsection{The Mathematical Graph}

A graph $\mathrm{G}$ is a methodical structure that consists of vertices, connected together by edges - to yield a system of interaction of the agents within the task at hand. Vertices represent nodes or agents in the system, and edges represent the corresponding relationships - so that the system seeks to study how the nodal relationships and interactions (via formation of node clusters or isolation) effects throughout the system. A powerful role of graphs is to bridge local feats within a node as it blossoms into a graph patterns, which helps to explain how all these impacts a complex effect that ripple via the graph (Ojugo et al, 2014).

A graph is graphically represented as network of nodes, and mathematically denoted as $\mathrm{G}=(\mathrm{V}, \mathrm{E}, \mathrm{w})$ - where $\mathrm{v}$ are a set of vertices or nodes, $\mathrm{E}$ is the set of relations or arcs; And, an (optional) $\mathrm{w}$ is the weight of each node. Each node has another set of nodes to which they are either linked or isolated from. Relationships are either weak or strong, and are measured via dyads D (Ojugo et al, 2016). A graph (directed/undirected) with nodes ( $\square \square \mathrm{V}$ ) and with ties (u,v) $\mathrm{E}$ allows interaction between the nodes in the graph. Graphs are from a specific family (and no algorithm considers all possible graphs).

If $\mathrm{G}=(\mathrm{V}, \mathrm{E})$ is a dynamic graph and $\mathrm{E}$ is set of time-stamped edges, (u,v)t $\square \mathrm{E}$ are interactions at time $\mathrm{t} \square \mathrm{Z}+$. If a product (data or innovation) is introduced therein, a node can assume one-of-three states. For a diffusion model, nodes are initialized active - so that in discrete time-steps cum evolution, an active node is exposed to an innovation for adoption. It continues till a stop criterion is satisfied or there are no more inactive nodes.

\subsection{Susceptible-Infect Diffusion Model}

The two major models namely (Ojugo et al, 2016):

\subsubsection{The Susceptible-Infect-Removed model}

here, a node may be in any of these states: (a) susceptible: if node has no virus but will become infected if exposed to it, (b) infected: if node has the virus and can pass it to others, and (c) removed: if node had virus but has been recovered or virus dies. The node is permanently immunized and can no longer participate in propagation, and a particular node cannot be infected twice. At $t=0$, an adversary inserts $d$ copies of a virus to some nodes. With node $\mathrm{x}$ infected, it has single chance to infect its neighbour node y that is currently exposed but uninfected. The probability that $\mathrm{x}$ succeeds in infecting $\mathrm{y}$ is Pxy. If $x$ succeeds, $y$ is infected at $t+1$; Else, $x$ tries again later (even if y gets infected by another neighbour). This 
process stops after $\mathrm{n}$-steps, if no more infection is possible. A node is infected exactly once (Kempe et al, 2003; Ojugo et al, 2016). If a graph of size $M$, has $M_{d}$ subset of nodes and $d$ copies of virus inserted, with propagation complete, $S\left(M_{d}, G\right)$ is expected number of infected nodes given by Eq. 1 as maximum exceeds all possible initial virus placements (Ojugo et al, 2016):

$$
S_{d}(G)=\max _{M_{d}} S\left(M_{j}, G\right)
$$

Subset $A_{d}=\arg \max _{M_{d}} S\left(M_{d}, G\right)$ equates to choices made by an adaptive adversary. $\mathrm{S}_{d}(\mathrm{G})$ is epidemic spread in G. Eq. 2 defines the expected epidemic spread of randomized adversary of the $d$ viruses placed on the network:

$$
S_{d}^{\prime}(G)=\mathrm{E}_{\mathrm{M}_{\mathrm{d}}}\left[S\left(M_{d}, G\right)\right]
$$

2.2.2 The Susceptible-Infect-Susceptible model here, a node is cured but not immunized. Thus, node can be re-infected as it switches between susceptible and immunized. The Dynamic spread model, allows viruses to use a dynamic birth-death event to evolve overtime. It continues to spread, or eventually die. An infected node x spreads the virus to node y at time $\mathrm{t}$ with infection rate $\frac{\beta}{\delta}$ and probability $\beta$. Also, an infected node may recover with probability $\delta$. With its adjacency matrix $\mathrm{T}, \lambda_{1}(\mathrm{~T})$ is largest eigen-value of $\mathrm{T}$; And condition $\frac{\beta}{\delta}<\frac{1}{\lambda_{1}(T)}$ holds as epidemic threshold, and is sufficient for quick recovery (Ganesh et al, 2005; Wang et al, 2003).

\subsection{Rationale for Use of Social Graph}

Use of graph-based approach seeks to analyze relationships in large graphs for these reasons (Ojugo et al, 2014):

a. Empirically investigating graph feats and relations therein for HBV propagation on a social graph is quite tedious and difficult.

b. Diffusion offers us a direct relationship between clusters and their corresponding cohesiveness; while, helping us to capture a graph's dynamic structure via clustering for easy comparison of result obtained.

c. Social graphs allow us to effectively explore parametric feats such as path dependence (i.e. a few minor shocks and insignificant events along the way within a graph) which in turn can alter the course of history. As thus, diffusion is an extremely fragile task with respect to small shocks; And in turn, highly path-dependent.

d. The need to acquire graph data in time, often complicates such empirical studies, and particularly for such complex patterns of interactions in a small world-graph.

e. Social graphs often suggest that emergent feats from local interactions are highly unbiased as they fully harness agent-based modeling potentials to seek out complex feats in social systems via the analysis of data generated.

f. A graph-based diffusion of innovation assumes certain dispositions for a number of nodes, and seeks to observe its nodal patterns as they emerge from interactions.

g. Graph diffusion model involves thought-outexperiments to learn about complex adaptive systems rather than seek to build valid representation of a real-world system.

Experiment seeks to explore rate of HBV infection in the Niger Delta Region, and to find the expected number of final adopters (those infected) alongside the graph parameters with the nodes' internal decision rules and position in the graph as they locally interact over time as exposed in the graph-based diffusion model. As such, the study is more interested in the local emergent feats emanating from large-scale effects of such interacting nodes of the entire supply network.

\section{MATERIALS AND METHODS 3.1 Data Gathering}

Sample dataset is presented in table 1 via research survey, comprising of a 2-phase questionnaire to collect tele-medical and demographic data. A total of 30,000 cases understudied from the various hospitals and medical experts spread across the 30 selected hospitals in Niger Delta Region in Nigeria.

Table 1: Dataset Fact-Sheets for Health

\begin{tabular}{|l|l|}
\hline Network Feats & $\begin{array}{l}\text { Estimated } \\
42 \text { million }\end{array}$ \\
\hline Population in Niger Delta & $\begin{array}{l}\text { Lower-middle- } \\
\text { income }\end{array}$ \\
\hline Country Classification & $\$ 2177.99$ \\
\hline $\begin{array}{l}\text { Gross National Income Per Capita (in } \\
\text { 2016) }\end{array}$ & $3.7 \%$ \\
\hline $\begin{array}{l}\text { Total Health Expenditure of GDP } \\
(2017)\end{array}$ & $\$ 3.5$ \\
\hline $\begin{array}{l}\text { Per capita Government Health } \\
\text { expenditure 2017 }\end{array}$ & 52 \\
\hline Life expectancy at birth (2017) & 0.527 \\
\hline Human Development Index (2015) & 18 \\
\hline Median Age In Years (2017) & 5.5 \\
\hline Total Fertility Rate per Woman (2017) & $30-180$ days \\
\hline HBV Detection Period & $4-6$ months \\
\hline HBV Infection incubation period & \\
\hline
\end{tabular}

Table 2: Dataset Fact-Sheets for Health

\begin{tabular}{|l|l|}
\hline Graph Feats & Description and Encoded Values \\
\hline Incubation Time & Between 3-to-6 months \\
\hline HBV_PCR & $\begin{array}{l}0 \text { for infected and 1 for non-infected } \\
\text { patients }\end{array}$ \\
\hline Gender & $\begin{array}{l}0 \text { for Male } \\
\text { Value 1 for Female }\end{array}$ \\
\hline Age & In Years \\
\hline $\begin{array}{l}\text { Residence } \\
\text { Settlement }\end{array}$ & $\begin{array}{l}\text { 0 for Rural, 1 for Semi-Urban and 2 for } \\
\text { Urban settlement }\end{array}$ \\
\hline
\end{tabular}




\begin{tabular}{|c|c|}
\hline Job & $\begin{array}{l}\text { Occupational category for Hepatitis } \\
1 \text { for Doctor (Faculty member), } 2 \text { for } \\
\text { Doctor (Student concession), } 3 \text { for } \\
\text { Surgeon (Faculty member), } 4 \text { for } \\
\text { Surgeon (Student concession), } 5 \text { for } \\
\text { Dentist, } 6 \text { for Medical student, } 7 \text { for } \\
\text { Nursing supervisor, } 8 \text { for Nurses, } 9 \text { for } \\
\text { Nursing student, } 10 \text { for Laboratory } \\
\text { Technician, } 11 \text { for Worker, } 12 \text { for } \\
\text { Paramedic, } 13 \text { for Laundry worker, } 14 \\
\text { for other medical personnel }\end{array}$ \\
\hline Schisto & $\begin{array}{l}\text { Schistosomiasis infection is encoded as } 0 \\
\text { for NO and } 1 \text { for YES }\end{array}$ \\
\hline Syringe Handling & $\begin{array}{l}\text { History of handling syringes on the job } \\
3 \text {-to-6-months preceding their enrolment: } \\
0 \text { for Nil, } 1 \text { for once in time interval, } 2 \\
\text { for dealing twice, } 3 \text { for dealing from } 3 \text { to } \\
5 \text { times, and } 4 \text { for dealing more than } 5 \\
\text { times }\end{array}$ \\
\hline Needlestick & $\begin{array}{l}\text { History of needlestick injuries in the year } \\
\text { prior to the enrolment: } 0 \text { for Nil, } 1 \text { for } \\
\text { once, } 2 \text { for twice, } 3 \text { for } 3 \text {-to- } 5 \text { times, and } \\
4 \text { for more than } 5 \text { times }\end{array}$ \\
\hline ALT & $\begin{array}{l}\text { Serum alanine aminotransferase, this } \\
\text { enzyme test is measured to see if the } \\
\text { liver is damaged or } \\
\text { diseased (Normal ranges Female: } 32 \text {, } \\
\text { Male: } 42 \text { ) }\end{array}$ \\
\hline AST & $\begin{array}{l}\text { An aspartate aminotransferase, this } \\
\text { enzyme test is measured to Check for } \\
\text { liver damage and Check on the success } \\
\text { of treatment for liver disease. (Normal } \\
\text { ranges Female: } 32 \text {, Male: } 42 \text { ) }\end{array}$ \\
\hline Hepatitis ELISA & $\begin{array}{l}\text { ELISA is a blood test for HCV antibody } \\
\text { produced by when it is infected with the } \\
\text { hepatitis virus. Value } 0 \text { for Negative and } \\
1 \text { for Positive }\end{array}$ \\
\hline HBsAg_ELISA & $\begin{array}{l}\text { HBV Surface Antigen, this test identifies } \\
\text { active infection by the HBV: Value } 0 \text { : } \\
\text { Negative and Value 1: Positive }\end{array}$ \\
\hline
\end{tabular}

Study uses the HBV spread as its innovation. It first seeks convergence in time of final number of persons exposed to the HBV and subsequent infection - with these goals: (a) do participants in this experiment observe WHO's safe plans, acknowledge HBV's infection high rate of fatality rate with imminent death - if, they do not stay ahead of the endemicity, and (b) the right machinery and measures are needed to steer such new vehicle to help eradicate the HBV propagation in Nigeria as a whole. Data adoption time is based on study initiation date, and not subject to errors. Recall, that errors are normally distributed. Study does not wish to discuss the effect of the graph structure on convergence time, nor effect of clustering on the diffusion model/process. Innovations diffuse faster on highly-clustered graph. Our experimental model seeks the expected number of final adopters as a function of time-dependent convergence task, the graph threshold (value at which a node exposed to HBV becomes infected), threshold value on nodes' behavioral evolution and their corresponding disposition towards the HBV infection as the innovation.

\subsection{Validating the Graph-Model Approach}

Researchers employ Cytoscape in the design of the nodal relationships and graph. Effectiveness of model is tested via the lift chart. The purpose was to determine which model gave the highest percentage of correct predictions for simulating patients that will in the near future be diagnosed with HBV infection. The chart also provides visual means to ascertain if there was sufficient data to learn patterns in response to the predictable feats in the dataset

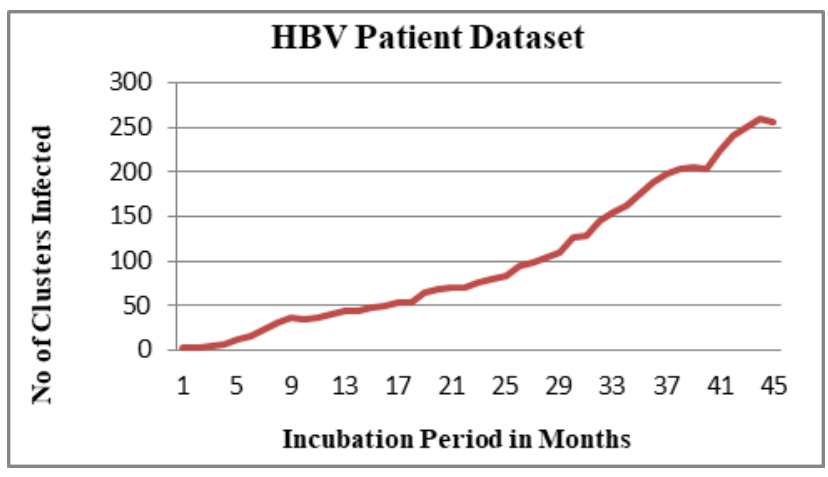

Figure 1: Prediction for adoption of $\mathrm{HBV}$ via the patient Dataset

Result shows model captured target population for HBVinfected patients using at least $50 \%$ of the dataset as test data.

\section{EXPERIMENTAL FRAMEWORKS}

The health-incident relation is modeled against 7-structural dimensions that manifest in various forms: (a) time structure, (b) emotional intensity, (c) mutual intimacy and (d) reciprocal services, (e) topology, (f) emotional support, and (g) social status and affiliation. These structural variables are substituted with other simple proxies such as communication recency, interaction reciprocity, mutual friendship and frequency of the interaction (Ojugo et al, 2016). Ojugo et al (2014) in Gilbert and Karahalois (2009) Potential feedback as it benefits user is expressed in Eq. 3 as a linear combiner, where $\mathrm{Ri}$ is number of predictive variables, ei is error term, $\mathrm{Di}$ is dyads pairs, $\mathrm{Gi}$ is graph structure and EIi are external influences.

$$
S_{i}=\propto+\beta R_{i}+\gamma D_{i}+N_{i}+E I_{i}+e_{i}
$$

Acemolgu et al (2012) in small-world graphs, a seednode delivers the innovation through an either sparse/dense graph.

Highly-clustered graphs have shorter-path length and larger clusters with small cardinality - resulting in a larger expected number of final adopters. The small world graph benefits the diffusion (contagion) process as it helps to reinforce adoption of the innovation, more likely exposes multiple adopters to the innovation and incurs overlapping influences through other feats such as short path-lengths during diffusion. Thus, our graph structure $\mathrm{G}_{i}$ which encodes our predictive variable(s) in the health-incident graph with respect to: (a) relations history, (b) reciprocity, and (c) clusters and its coefficients - is Eq. 4.

$$
\begin{aligned}
G_{i}=P_{\theta, G}+\lambda_{0} \mu_{L} & +\lambda_{1} \operatorname{Med}_{L}+\sum_{t=0}^{t-1} \sum_{i \in L} \lambda_{t}\left(s-\mu_{L}\right)^{t} \\
& +\lambda_{5} \operatorname{Min}_{L}+\lambda_{6} \operatorname{Max}_{L}
\end{aligned}
$$

$\mathrm{G}_{i}$ uses: (a) $P_{\theta, G}$ as graph's probability distribution of nodes, (b) $\mu /$ Med is nodal and system threshold, (c) $\sum_{t=0}^{t-1} \sum_{i \in L} \lambda_{t}(s-$ $\left.\mu_{L}\right)^{t}$ is learning heuristic (function of its convergence in time as outcome of diffusion), and (d) Max/Min as boundary limit 
of final adopters. With $i$ 's neighbour $(j)$ having potentially unique set of mutual friends, small-world graph must account for: (a) mean number of relations for clustering among nodes, (b) variance in the number of relations for nodal/joint degree of separation, (c) kurtosis of clusters and its coefficient, (d) min number of relations accounts for local density and degree of distribution, and (e) max number of relations accounts for reciprocity (Gilbert and Karahalois, 2009; Ojugo et al, 2016).

The stochastic threshold of node $i$ from a linear threshold model: If $\mathrm{M}=\{1,2,3, \ldots \mathrm{N}\}$ has $\mathrm{V}$-vertices, E-edges and $\mathrm{w}$ weighted probabilities for its nodal feats given by G(V,E,w). A node's personal network has a neighbour set of the agent $\mathrm{i} \in \mathrm{M}$ given by $\mathrm{Pi}(\mathrm{G})=\{\mathrm{j} \mid(\mathrm{j}, \mathrm{i}) \in \mathrm{E}\}$ to consist of agents who can potentially influence agent $i$ in $\mathrm{G}$. A time $\mathrm{t}=\{0,1,2, \ldots, \mathrm{n})$, we have a seednode $\Phi(0) \subseteq \mathrm{M}$ (i.e. set of innovators exposed with threshold uniform between [0.5,1]). This reflects our lack of knowledge of a node's true threshold (Kempe et al, 2005). The expected number of final adopters, is given by Eq. 5:

$$
F A_{d}=\frac{\left|\Phi(0) \cap P_{i}(\mathrm{G})\right|}{\left|P_{i}(\mathrm{G})\right|} \geq \phi_{i} \Rightarrow i \in \Phi([0,1])
$$

At $\mathrm{t} \geq 0$, we generalized that: a node $i \in \mathrm{M} / \mathrm{\cup}_{l=0}^{t-1} \Phi(l)$ will adopt at $t$ of linear threshold given by Eq. 6 .

$$
F A_{d}=\frac{\left|\left\{\mathrm{U}_{l=0}^{t-1} \Phi(l)\right\} \cap P_{i}(G)\right|}{\left|P_{i}(G)\right|} \geq \phi_{i} \Rightarrow i \in \Phi(t)
$$

\subsection{Result Findings and Discussions}

With the adoption of a linear combiner model to predict HBV infection in the Niger Delta Region using the sample data allows us to full explore the underlying feats in the dataset. $s_{i}$ is tie-strength of agents $i, \mathrm{R}_{\mathrm{i}}$ is number of predictive variables for task at hand, $e_{i}$ is the error term in tie strength, $G_{i}$ is graph structure. $D i$ all pairwise relationship between variables shows a $90 \%$ or greater completion rate. This is further resolved via reciprocity. Result shows that where seedset nodes influence over the other nodes are uniformly distributed over the graph. External influence and path dependence only accounts for about $11.8 \%$ of deflection from true purpose (as in table 3 ).

Table 3: HBV Infection Propagation Time

\begin{tabular}{|l|l|l|l|l|l|l|}
\hline & $\begin{array}{l}\text { Dependent } \\
\text { Variables }\end{array}$ & $\boldsymbol{\mu}$ & $\boldsymbol{+}_{\boldsymbol{i}}$ & $+\boldsymbol{G}_{\boldsymbol{i}}$ & $\boldsymbol{+}_{\boldsymbol{i}}$ & $\boldsymbol{E}_{\boldsymbol{i}}$ \\
\hline 1 & $\begin{array}{l}\text { How constant have } \\
\text { you been here in the } \\
\text { last } \\
\text { month?(Duration) }\end{array}$ & 0.67 & 0.94 & 0.87 & 0.89 & 0.21 \\
\hline 2 & $\begin{array}{l}\text { How long you been } \\
\text { handling body fluid } \\
\text { exchange materials } \\
\text { on this job? } \\
\text { (Intensity) }\end{array}$ & 0.47 & 0.87 & 0.78 & 0.89 & 0.10 \\
\hline 3 & $\begin{array}{l}\text { How helpful has } \\
\text { this project been? } \\
\text { (Social Distance) }\end{array}$ & 0.23 & 0.42 & 0.34 & 0.43 & 0.19 \\
\hline 4 & $\begin{array}{l}\text { How attached are } \\
\text { you to patients with } \\
\text { HV? (Emotional } \\
\text { Support) }\end{array}$ & 0.43 & 0.90 & 0.92 & 0.95 & 0.21 \\
\hline
\end{tabular}

\begin{tabular}{|l|l|l|l|l|l|l|}
\hline 5 & $\begin{array}{l}\text { What is the recent } \\
\text { communication you } \\
\text { made unknowingly } \\
\text { with such HV } \\
\text { patients? (Intimacy) }\end{array}$ & 0.28 & 0.81 & 0.65 & 0.78 & 0.10 \\
\hline 6 & $\begin{array}{l}\text { Working in this } \\
\text { facility, is it about } \\
\text { the money or the } \\
\text { sense to help the } \\
\begin{array}{l}\text { HV patients? } \\
\text { (Reciprocity) }\end{array}\end{array}$ & $\begin{array}{l} \\
\text { How many mutual } \\
\text { friends do you } \\
\text { share, do you share } \\
\text { the same interest } \\
\text { (interest overlap) } \\
\text { and how many } \\
\text { clusters do you both } \\
\text { belong to in- } \\
\text { common? } \\
\text { (Structural } \\
\text { Distance) }\end{array}$ & 0.80 & 0.82 & 0.86 & 0.34 \\
\hline
\end{tabular}

Table 4: Convergence of Expected Infected Nodes with External Influence on Adoption

\begin{tabular}{|l|l|l|l|l|l|l|l|}
\hline Adopter & \multirow{2}{*}{$\begin{array}{l}\text { Ext. } \\
\text { Category }\end{array}$} & \multicolumn{4}{|l|}{ Personal network: direct ties } & \\
\cline { 3 - 8 } & & $\mu$ & $\delta$ & Low & Ave & High & $\begin{array}{l}\text { System } \\
\text { Total }\end{array}$ \\
\hline Early & 1.1 & 0.61 & 0.42 & 7.2 & 8.9 & 12.9 & $29 \%$ \\
\hline $\begin{array}{l}\text { Early } \\
\text { Majority }\end{array}$ & 2.1 & 0.52 & 0.24 & 5.1 & 5.2 & 10.6 & $20.9 \%$ \\
\hline $\begin{array}{l}\text { Late } \\
\text { Majority }\end{array}$ & 2.1 & 0.32 & 0.13 & 8.9 & 6.1 & 8.9 & $23.9 \%$ \\
\hline Laggards & 6.5 & 0.42 & 0.29 & 10.9 & 7.8 & 7.5 & $26.2 \%$ \\
\hline Total & & & & & & & $100 \%$ \\
\hline
\end{tabular}

Table 4 shows an average of $49.9 \%$ of the entire cluster adopts (infected by HBV) with $90 \%$ significance. Result shows that a node's time-of-adoption is associated with the proportion of adopters (and seednode) in the social graph as well as those associated with the proportion in a node's personal network. Thus, $49 \%$ of exposed individuals to HBV are classified to hit the expected threshold in relation to their adoption time and to the social graph. Also, a consequent corresponding $23.9 \%$ are more innovative as late majority adopter (as infected by HBV) and thus, they will be infected after and/or until some portion of their entire graph system has adopted the innovation. While, those in the laggard phase have either very low or very high thresholds.

Result shows that the external influence scores for each of the categories (low, average and high) adopters vary for agents who are innovative relative to the system. External influences here ranged from campaign, sentiments, urbanization effect, finance, gender etc.

\section{CONCLUSION}

Many studies with various manifestations of tie strength (Krackhardt, 1990; Haythornthwaite, 2002), allows capture of multiplicity and diversity views of participants who were asked to answer 7-tie strength questions. Participants moved a slider along a continuum to rate a friend as illustrated in table 
3. The continuum is chosen rather than a discrete scale for three-reasons: (a) relationships are in continuous (Granovetter, 1973). This study and many others are not poised to resolve if tie-strength is discrete of not, and have also not specified how many discrete tie-strength levels exist. The continuum to this end, bypasses that problem, (b) continuum lends itself to the modeling method, which is both stochastic and evolutionary, and (c) its application can round a continuous model's predictions to discrete-levels when and as needed and appropriate (Gilbert and Karahalois, 2009).

The study explores the relationship of the expected number of final adopter (our metrics), clustering effects, threshold values with path-dependence, network structure and seed cardinality - to suggest that the highly clustered networks with more seed-sets allowed for easier diffusion of innovation. While clustering and high clustering coefficients promotes diffusion where there exists seed node inside an agent's personal networks and social system, such cohesive and highly clustered sets are also quite difficult to penetrate when they are not targeted during initial seeding phase. In some cases, sampling strategy used to generate the agents for the diffusion process can create some errors in the time of adoption, alongside the external influences that acts on the system etc. These external influences such as finance, tribalism, race and gender etc - can also act as a motivator during each transaction that involves corrupt ethics, especially with such actors not being monitored. This will alter the outcome of the diffusion process significantly. A major reason why project was kept at 18 months is to seek time convergence and the acceptability of the initiative - that will help change actor perception, disposition and behaviour and consequently allow complete diffusion as actors create stronger ties.

\section{REFERENCES}

[1] Abraham, A., (2005). Handbook of Measuring System Design, John Wiley and Sons Ltd, ISBN: 0-470-021438, pp. $901-918$.

[2] Barakat, N.H., Bradley, A.P., Barakat, M.N.H., (2010). Intelligible support vector machines for diagnosis of diabetes mellitus, IEEE Transactions on Information Technology in Biomedicine, 14(4), pp 1114-1120

[3] Berks, G., Keyserlingk, D., Jantzeen J., Dotoli, M and Axer H. (2000). Fuzzy clustering: versatile means to explore medical database, ESIT, Aachen, Germany

[4] Beven, K. J and Binley, N.J., (1992). Knowledge driven models and computations, Wiley and Sons, Chichester, ISBN: 0-465-08245-3.

[5] Bishop, C. M., (1995). Neural networks for pattern recognition, Oxford University Press, ISBN: 0-34245230, pp.253-294.

[6] Branke, J., (2001a). Evolutionary Optimization in Dynamic Environments, Kluwer.

[7] Branke, J., (2001b). Reducing the sampling variance when searching for robust solution, Proc. of Man and Cybernetics, 14(6), pp 234-242.

[8] Canadian Diabetes Association. Standards of Medical Care in Diabetes 2014, Journal of Diabetes Care, 32, S13 - 16.

[9] Caudill M., (1987). Neural Networks Primer, AI Expert December, pp.46-52.

[10] Chinenye, S and Young, E., (2011). State of diabetes care in Nigeria: a review, The Nigerian Health Journal, 11(4), pp101-106

[11] Coello, C., Pulido, G and Lechuga, M., (2004). Handling multiple objectives with particle swarm optimization, In Proceedings of Evolutionary Computing, Vol. 8, pp 256-279.

[12] Conway, A. J., Macpherson, K and Brown, J., (1998). Delayed time series predictions with ANN, J. of Neuro computing, 18, pp.81-89.

[13] Dawson, C and Wilby, R., (2001a). Comparison of neural networks in river flow forecasting, J. of Hydrology and Earth Science, SRef-ID: 16077938/hess/2001-3-529.

[14] Dawson, C and Wilby, R., (2001b). Hydrology modeling using neural network, J. Programming in Physics and Geography, 25, pg 80-108

[15] Edo, A.E., Edo, G.O., Ohehen, O.A., Ekhator, N.P and Ordiah, W.C., (2015). Age and diagnosis of type-2 diabetes seen in Benin City Nigeria, African Journal of Diabetes Medicine, 23(1), pp18-19.

[16] Fausett L., (1994). Fundamentals of Neural Networks, New Jersey: Prentice Hall, pp.240.

[17] Giles, D and Draeseke, R., (2001). Economic Model Based on Pattern recognition via fuzzy C-Means clustering algorithm, Economics Dept Working Paper, EWP0101, University of Victoria, Canada.

[18] Goldenberg, R and Punthakee,, Z (2013). Definition, classification and diagnosis, prediabetes and metabolic syndrome, 37(1), S8-S11.

[19] Guo, W.W and Xue, H., (2011) An incorporative statistic and neural approach for crop yield modelling and forecasting, Neural Computing and Applications, 21(1), pp109-117

[20] Hall, M. J., (2001). How well does your model fit data?, J. Hydroinformatics, 3(1), pp.49-55.

[21] Haykin, S., (1999). Neural networks, comprehensive foundation, Prentice Hall: New Jersey, pp. 23 - 89.

[22] Heppner, H and Grenander, U., (1990). Stochastic nonlinear model for coordinated bird flocks, In Krasner, S (Ed.), The ubiquity of chaos (pp.233-238). Washington: AAAS.

[23] Hjemfelt, A and Wang, M., (1993). Artificial neural networks as unit hydrograph applications, Proc. of Engineering Hydrology, pp.754-759

[24] Inan, G and Elif, D., (2005). Adaptive neuro-fuzzy inference system for classification of EEG using wavelet coefficient, retrieved from http://www.rorylewis.com/PDF/04

[25] Jain, A. and Srinivasulu, S., (2004). Development of effective, efficient rainfall-runoff models using integration of deterministic, real-coded GA and ANN, Water Resources, 40(4), pp. $23-45$.

[26] Jang, J.S., (1993). Adaptive fuzzy inference systems, IEEE Transactions on Systems, Man and Cybernetics, vol.23, pp.665-685.

[27] Khashei, M., Eftekhari, S and Parvizian, J (2012). Diagnosing diabetes type-II using a soft intelligent 
binary classifier model, Review of Bioinformatics and Biometrics, 1(1), pp 9-23.

[28] Kuan, C and White, H., (1994). Artificial neural network: econometric perspective", Econometric Reviews, Vol.13, Pp.1-91 and Pp.139-143.

[29] Ludmila I. K. (2008), Fuzzy classifiers Scholarpedia, 3(1), pp2925

[30] Mandic, D and Chambers, J., (2001). Recurrent Neural Networks for Prediction: Learning Algorithms, Architectures and Stability, Wiley \& Sons: New York, pp56-90.

[31] Minns, A., (1998). Artificial neural networks as subsymbolic process descriptors, published $\mathrm{PhD}$ Thesis, Balkema, Rotterdam, Netherlands

[32] Nascimento L., (1991). Comparative Genomus of two Leptospira interrogans Serovirs, http://jb.asm.org/cgi/content/full/186/7/2164

[33] Ojugo, A., (2012). Artificial neural networks gravitational search algorithm for rainfall runoff modeling in hydrology, unpublished $\mathrm{PhD}$ Thesis, CS Department: Ebonyi State University Abakiliki, Nigeria.

[34] Ojugo, A., Eboka, A., Okonta, E., Yoro, R and Aghware, F., (2012). GA rule-based intrusion detection system, Journal of Computing and Information Systems, 3(8), pp 1182 - 1194.

[35] Ojugo, A.A., and Yoro, R., (2013a). Computational intelligence in stochastic solution for Toroidal Queen, Progress in Intelligence Computing and Applications, 2(1), pp $46-56$.

[36] Ojugo, A.A., Emudianughe, J., Yoro, R.E., Okonta, E.O and Eboka, A., (2013b). Hybrid neural network gravitational search algorithm for rainfall runoff modeling, Progress in Intelligence Computing and Application, 2(1), doi: 10.4156/pica.vol2.issue1.2, pp 22 $-33$.
[37] Ojugo, A.A., Ben-Iwhiwhu, E., Kekeje, D.O., Yerokun, M.O and Iyawa, I.J.B., (2014). Malware propagation on time varying network, Int. J. Modern Edu. Comp. Sci., $8, \mathrm{pp} 25-33$

[38] Ojugo, A.A., Eboka, A.O., Yoro, R.E., Yerokun, M.O and Efozia, F.N., (2015). Hybrid model for early diabetes diagnosis, Mathematics and Computers in Science and Industry (A Mathematics and Computers in Science and Engineering Series), 50: 176-182, ISBN: 978- 1- 61804- 327- 6, ISSN: 2227- 4588

[39] Perez, $M$ and Marwala, T., (2011). Stochastic optimization approaches for solving Sudoku, IEEE Transaction on Evol. Comp., pp.256-279.

[40] Reynolds, R., (1994). Introduction to cultural algorithms, Transaction on Evolutionary Programming (IEEE), pp.131-139.

[41] Ursem, R., Krink, T., Jensen, M.and Michalewicz, Z., (2002). Analysis and modeling of controls in dynamic systems. IEEE Transaction on Memetic Systems and Evolutionary Computing, 6(4), pp.378-389

[42] Vaarala, O., Knip, M., Paronen, J., Hamalainen, A.M., Muona, P., Vaatainen, M., Ilonen, J., Simell, O and Akerblom, H.K., (1999). Cow's milk formula feeding induces primary immunization to insulin in infants at genetic risk for type-1 diabetes, Diabetes, 8(7), pp13891394.

[43] Davis, K., (2018). Everything you need to know about Hepatitis B, Medical News Today, Last updated January $22 \quad 2018 \quad$ [online https://www.medicalnewstoday.com/articles/306288.ph $\mathrm{p}$

[44] Wilkins, T., Zimmerman, D and Schade, R.R., (2010). Hepatitis B: diagnosis and treatment, American Family Physician, 81(8), pp 965-972. [online]: www.aafp.org/afp. 